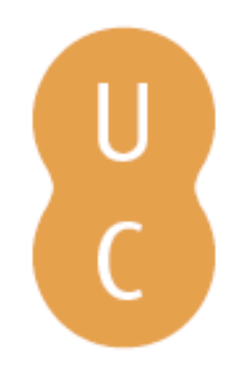

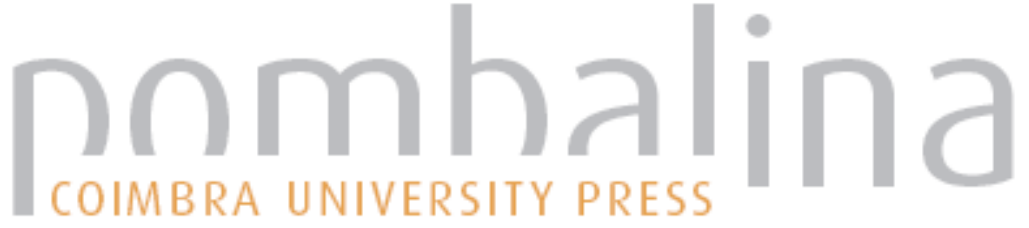

\section{O cómico e a violência: a autoridade da vítima}
Autor(es):
Ribeiro, António Sousa
Publicado por: Imprensa da Universidade de Coimbra
URL persistente:
URI:http://hdl.handle.net/10316.2/42333
DOI:
DOl:https://doi.org./10.14195/978-989-26-1308-6_23

Accessed : $\quad$ 26-Apr-2023 10:32:15

A navegação consulta e descarregamento dos títulos inseridos nas Bibliotecas Digitais UC Digitalis, UC Pombalina e UC Impactum, pressupõem a aceitação plena e sem reservas dos Termos e Condições de Uso destas Bibliotecas Digitais, disponíveis em https://digitalis.uc.pt/pt-pt/termos.

Conforme exposto nos referidos Termos e Condições de Uso, o descarregamento de títulos de acesso restrito requer uma licença válida de autorização devendo o utilizador aceder ao(s) documento(s) a partir de um endereço de IP da instituição detentora da supramencionada licença.

Ao utilizador é apenas permitido o descarregamento para uso pessoal, pelo que o emprego do(s) título(s) descarregado(s) para outro fim, designadamente comercial, carece de autorização do respetivo autor ou editor da obra.

Na medida em que todas as obras da UC Digitalis se encontram protegidas pelo Código do Direito de Autor e Direitos Conexos e demais legislação aplicável, toda a cópia, parcial ou total, deste documento, nos casos em que é legalmente admitida, deverá conter ou fazer-se acompanhar por este aviso.

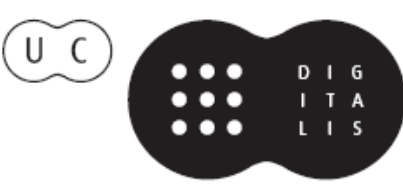



O Cóm ICO E A VIOLÊNCIA:

A A UTORIDADE DA VÍTIMA

António Sousa Ribeiro

Resumo: $O$ artigo propõe-se contribuir para a análise do problema da relação entre o cómico e a violência, concedendo especial atenção a textos autobiográficos, em particular da literatura do Holocausto, e ao uso do cómico e do grotesco como modos de recusa do estatuto da vítima.

Palavras-chave: violência; holocausto; vítima; cómico.

Abstract: The article is a contribution to an analysis of the problem of the relationship between the comic and violence, with special emphasis on autobiographical texts, in particular in the framework of Holocaust literature, and on the use of the comic and the grotesque as ways of refusing the status of the victim.

Keywords: violence; holocaust; victim; comic. 
Onde há violência, há vítimas da violência, isto é, seres humanos em cujos corpos a violência se inscreveu e que, de muito diferentes maneiras, terão de transportar consigo essa inscrição num futuro irremediavelmente marcado pela experiência do sofrimento. Como escreve a filósofa francesa Simone Weil no seu grande ensaio "LIliade ou le poème de la force", a violência, por definição, reifica radicalmente as suas vítimas, degrada-as à condição de simples objetos. No capítulo sobre a tortura do seu livro Jenseits von Schuld und Sühne (Para além de culpa e expiação), Jean Améry demonstra essa reificação de um modo extremamente incisivo, definindo a tortura como a "negação radical do outro" (52) e vendo nela a completa "transformação do ser humano em carne" (idem: 50):

A pessoa torturada nunca mais deixa de se admirar de que tudo a que, conforme a inclinação, se possa chamar a sua alma ou o seu espírito ou a sua consciência ou a sua identidade se desvanece quando as articulações estalam e se estilhaçam. (idem: $57-58)^{1}$

A vítima sobrevivente encontra-se numa situação paradoxal: por um lado, tem de reivindicar o estatuto de vítima, tem de assumir a condição moral da vítima, para usar a expressão de Didier Fassin (Fassin e Rechtman), pois só assim pode exigir o direito a ser indemnizada, encontrar reconhecimento e manter viva a memória da violência sofrida; por outro lado, é forçada, ao mesmo tempo, a pôr em questão o próprio conceito de vítima, a recusar a fixação no papel da vítima, na medida em que este papel implique a redução permanente ao estado da reificação, como objecto de compaixão ou como alguém que, de algum modo, está irrevogavelmente preso por toda a eternidade ao ponto do sofrimento experimentado. Por

${ }^{1}$ Salvo indicação em contrário, as traduções são minhas. 
outras palavras, trata-se de reconquistar uma posição de sujeito, de reivindicar, em sentido literal, um estatuto de autoridade e, assim, afirmar de novo a identidade posta em causa pelo acto da violência. Como pode ler-se em Imre Kertész acerca do impulso motor da sua escrita:

. . . eu queria conquistar poder sobre a realidade que, por sua vez - de maneira muito efectiva - me tinha em seu poder. Eu queria sair da minha eterna condição de objecto e transformar-me em sujeito, queria nomear eu próprio, em vez de ser nomeado. (61)

Parafraseando a pergunta famosa de Gayatri Spivak sobre se "o subalterno pode falar?", poderia perguntar-se, neste contexto, se a vítima pode falar. É sabido como Spivak formula a sua pergunta em relação ao sujeito dominado no quadro da relação colonial enquanto relação de violência ou, mais exactamente, em relação à mulher colonizada, duplamente oprimida. Entretanto, sabemos bem que tanto o/a subalterno/a como a vítima podem muito bem falar - afinal, vivemos, nas palavras de Annette Wieviorka, na "era da testemunha”. A questão decisiva a formular, porém, continua a ser a questão das condições, tanto de articulação como de receção, em que pode processar-se esse falar. Estas condições exigem, nomeadamente, uma esfera pública em que o acto do testemunho possa esperar reciprocidade, isto é, pressupõem a disponibilidade dialógica para manter aberto um espaço de ressonância adequado para a voz - ou o grito - da vítima. Por outro lado, não são menos decisivas as modalidades da fala, isto é, essa voz tem de ser capaz de se articular de uma forma que a faça não só ser ouvida, mas também constitua efetivamente a autoridade da vítima no sentido atrás referido. Por outras palavras, levantam-se, neste contexto, questões que têm que ver com a retórica do testemunho e que, em aspetos essenciais, são também questões estéticas e estão 
relacionadas em aspetos decisivos com estratégias discursivas que permitem, de diferentes modos, refratar e criar distância relativamente à experiência do sofrimento e da violência. Neste aspeto, a vítima deve exibir verdadeiramente aquela "altivez do sofredor" de que fala Nietzsche na Nona Secção de Para além de bem e mal - num passo que, de forma inquietante, quase parece descrever a situação do sobrevivente de Auschwitz:

A altivez espiritual e o nojo de todo o ser humano que sofreu profundamente. . ., a certeza arrepiante, de que ele está totalmente repassado e impregnado, de, devido ao seu sofrimento, saber mais do que os mais inteligentes e sábios podem saber, de estar familiarizado e ter estado "em casa" em muitos mundos distantes e terríveis dos quais "vós nada sabeis!" . . . esta altivez espiritual silenciosa do sofredor, este orgulho do escolhido do conhecimento, do "iniciado", do quase sacrificado, acha necessárias todas as formas de disfarce, para se defender do contacto com mãos atrevidas e compassivas e, em geral, de tudo o que não seja seu igual na dor. (225)

Entre as "formas de disfarce", isto é, entre as estratégias retóricas que, por um lado, geram distância entre a vítima e as suas próprias experiências e, por outro, mantêm presente o abismo intransponível entre ela e aqueles que não partilharam essas experiências, a dimensão do cómico ocupa um lugar talvez inesperado, mas irrecusável. No plano estrutural, o cómico pressupõe sempre a latência de outras possibilidades do real e, nessa medida, através da produção de dissonância, implica um questionar da condição compacta e, aparentemente, imutável desse real. Mas será que o cómico pode ser um instrumento adequado lá onde, como em situações de violência extrema, essa condição compacta parece insuperável e total? Na verdade, o valor de posição do cómico na representação da violência constitui 
um tema entre todos difícil e delicado com que, até ao momento, a investigação só se tem ocupado de modo muito lateral. Não obstante, a questão da interligação entre o cómico e a violência não pode ser descartada, pode ser abordada a partir de diferentes exemplos marcantes e, nos últimos anos, tem vindo a merecer atenção crescente da investigação, incluindo da investigação sobre o Holocausto, como revela, por exemplo, toda a discussão em torno do filme de Robert Benigni, La vita è bella, que, na verdade, representa uma espécie de comédia sobre o tema do Holocausto. Mas também relativamente a obras anteriores, como, para citar apenas alguns exemplos, Jakob der Lügner (Jakob, o mentiroso), de Jurek Becker, Der Nazi und der Friseur (O nazi e o cabeleireiro), de Edgar Hilsenrath ou The King of the Jews (O rei dos Judeus), de Leslie Epstein, a questão do cómico se coloca, por vezes de modo drástico.

É sabido como nos campos e, sobretudo, nos guetos, apesar de ou, talvez, devido às terríveis condições de vida, o humor não deixava de fazer parte da vida quotidiana. Emanuel Ringelblum, o historiador judaico que, em condições desesperadas, se tornou cronista dos guetos polacos, incluiu nas suas notas sobre o gueto de Varsóvia uma coleção de anedotas que circulavam no gueto (Des Pres 1988). O humor, incluindo o auto-humor, é, neste contexto, uma estratégia de sobrevivência, faz parte da astúcia dos que estão radicalmente privados de direitos e que, dessa forma, num plano simbólico, conseguem fugir ao mundo totalitário da violência nazi e manter aberta a possibilidade, mesmo precária, da dissonância. Mas será que o riso é de todo em todo possível quando se trata da representação do Holocausto? Num ensaio dos anos 80 sobre "Holocaust Laughter", Terrence des Pres lembra que existe uma espécie de regra de decoro que exige que "o Holocausto seja abordado como um acontecimento solene ou mesmo sagrado, com uma seriedade que não admite qualquer reacção que possa obscurecer a sua enormidade ou desonrar os 
seus mortos" (217). Nestes termos, o código da representação do Holocausto exige que seja lançado um tabu sobre o riso. Todavia, na história da escrita sobre o Holocausto, este tabu tem sido muitas vezes quebrado, justamente em textos da autoria das vítimas e de sobreviventes diretos ou indiretos.

Terei de me limitar a abordar o problema a partir de alguns poucos exemplos. Uma questão essencial começa por ser a de saber não apenas "como é que se gera o riso" e, em concomitância, "quem se ri?", mas também quem tem um direito legítimo ao riso. Em A Investigação (Die Ermittlung), de Peter Weiss (Weiss, 1976), um drama-documento baseado na montagem literal de passos das atas do processo de Auschwitz de 1963-65, sem dúvida uma obra canónica da literatura do Holocausto, surgem momentos de riso. Mas quem se ri são os acusados, que contam uns aos outros anedotas sobre os sobreviventes, não as testemunhas, cujas declarações se processam estritamente no registo da seriedade profunda da recordação da violência sofrida. Neste caso, portanto, o humor é utilizado como instrumento de caraterização da abjecção moral dos criminosos. Não se espera, em conformidade, que o leitor ou o espetador se ria, pelo contrário, a expetativa de receção visa inequivocamente a empatia com a seriedade do destino de sofrimento das vítimas. O mesmo acontece em muitos, seguramente a maioria, dos "disfarces" da experiência do Holocausto. Mesmo quando, como na novela gráfica Maus de Art Spiegelman, se recorre a meios tradicionais do cómico, no caso a forma do "comic book", na vertente da história de animais ilustrada - como é sabido, todas as personagens sofrem o estranhamento da representação como animais, os judeus como ratos e os nazis como gatos - não se visa um efeito cómico. Em Maus, a história do pai de Spiegelman, um sobrevivente de Auschwitz, e, num segundo nível, também a história da relação difícil do filho com o destino do pai, não há, na verdade, nada que explore a possibilidade do riso, embora a moldura narrativa pressuponha a 
dimensão do grotesco e, na narração, não deixe de haver momentos com acentuado potencial cómico.

Em contrapartida, é possível aduzir exemplos em que o cómico constitui um aspeto essencial e é justamente em relação a esses exemplos que a pergunta "a quem é lícito rir?" se impõe de uma forma muito particular. O conto Mutters Courage ( $A$ coragem da mãe), do escritor de origem húngara George Tabori, que sobreviveu aos anos do nazismo no exílio enquanto o pai morria em Auschwitz, narra a história da sobrevivência da mãe do autor em Budapeste. De um modo que se suporia totalmente inverosímil, Elsa Tabori, que, presa numa rua de Budapeste por guardas SS, é levada para um local de detenção para ser deportada, consegue representar de modo convincente o papel de alguém detentor de um passaporte protetor da Cruz Vermelha sueca, só casualmente esquecido em casa. A história é tida como boa e Elsa é libertada. Contra todas as regras da precaução, a mãe de Tabori estava, como era seu costume semanal, a caminho da tarde de jogo de cartas que de modo nenhuma queria dispensar. Uma vez escapada ao perigo mortal pela sua astúcia - e por uma sorte indescritível - consegue chegar ainda a tempo a casa das amigas, onde as amadas cartas já estão à sua espera.

Em Mutters Courage, como noutros textos de Tabori sobre o Holocausto, à cabeça a narrativa, depois transformada em drama, Mein Kampf, uma sátira a Hitler, não faltam pormenores cómicos, de sugestão surreal, muitas vezes em tom de farsa. Na verdade, os textos de Tabori fazem rir, ou pelo menos, repetidamente, sorrir. A narrativa sobre a mãe foi passada ao cinema em 1994, com realização de Michael Verhoeven, tendo o filme sido estreado em 1995. O verbete no Lexikon des internationalen Films é extremamente relevante para o problema que tenho vindo a tratar:

Primeira "comédia negra alemã sobre o Holocausto", cujos momentos grotescos e de pura farsa não escandalizam, sabendo-se 
da autoria "judaica" do guião. Impressiona, tanto como tentativa séria de pôr a nu o mecanismo complicado da máquina de destruição como também no esforço de dar forma ao inconcebível. (Katholisches Institut für Medieninformation, 1995)

Como se vê, da perspetiva desta obra de referência, os momentos cómicos do filme só podem ser justificados pelo facto de o autor ser judeu. Pressupõe-se implicitamente que um autor não judeu não teria direito ao uso do cómico no tratamento de um tema assim. Traça-se, assim, com clareza uma linha de fronteira que coloca questões de muito difícil resposta. Pode bem formular-se objeções ao traçar dessa linha de fronteira, mas ela é irrecusável: se se recordar a que é talvez a sentença mais famosa de Tabori, "der kürzeste deutsche Witz ist Auschwitz"2 -, justifica-se, sem dúvida, perguntar se esta insondável frase, em si mesma dificilmente suportável, seria de todo em todo aceitável se não soubéssemos que o seu autor é um judeu cujo pai morreu no campo de extermínio.

A epígrafe a Mein Kampf, de Tabori, oferece uma pista importante de compreensão. De modo claramente programático, a epígrafe cita os dois versos do epigrama "Die Scherzhaften" ("Os joviais"), de Hölderlin: "Sempre a brincar e gracejar? Outra coisa não podeis! Ó amigos! Fere-me / Isto a alma, pois só desesperados a tal são compelidos." (1991: 5). Só desesperados a tal são compelidos: através desta epígrafe, o cómico é justificado como instrumento necessário para aqueles a quem nenhum outro meio já resta. É, assim, sublinhado enfaticamente como signo da possibilidade de sentido numa situação que parece excluir esta possibilidade.

Se recuarmos à época imediatamente posterior à Primeira Guerra Mundial, encontramos esta questão da legitimidade do riso explicitamente tematizada num lugar central. Estou a referir-me à defesa

\footnotetext{
${ }^{2}$ A sentença é intraduzível: "A mais curta anedota (Witz) alemã é Auschwitz".
} 
do olhar satírico no prefácio de Karl Kraus à sua "tragédia em cinco atos com prólogo e epílogo", Die letzten Tage der Menschheit (Os últimos dias da humanidade). Este prefácio está escrito da perspetiva da voz satírica autoral. Kraus designou a guerra repetidamente como "Carnaval trágico" e, em conformidade, o tratamento satírico do tema neste drama incomensurável evidencia permanentemente traços marcadamente cómicos - na verdade, o drama, a meu ver, pode ser visto como uma obra-prima de entrelaçamento entre os géneros clássicos da sátira patética e da sátira irónica. No prefácio, partindo da citação da fala final de Horatio em Hamlet, Kraus assume explicitamente a máscara da testemunha fiel à missão de "narrar com verdade" os horrores sofridos. É este papel de testemunha que confere ao autor satírico - e só a ele - o direito ao riso:

O humor não é senão a acusação lançada a si próprio por alguém que não enlouqueceu à ideia de ter suportado testemunhar as coisas deste tempo no seu perfeito juízo. Além dele, que transfere para a posteridade a vergonha de em tal ter tido parte, ninguém mais tem direito a esse humor. Os contemporâneos, que consentiram que acontecesse o que aqui fica registado, renunciem ao direito de rir, em prol do dever de chorar. (17)

O conceito de posteridade desempenha neste contexto um papel fundamental, já que aponta para a possibilidade de que, num futuro que não deixa de ser incerto, possam existir possibilidades de compreensão que vão ao encontro da intenção do autor satírico de entender e denunciar a Guerra Mundial como um acontecimento cujo absurdo não é acessível apenas com a seriedade do pathos, antes tem também de ser posto a nu com os meios do cómico. Neste sentido, aquele riso a que apenas a posteridade terá talvez direito não representa simplesmente uma descarga emocional ou uma diversão sem consequências: é, sim, parte de um processo de construção de 
conhecimento complexo sobre um acontecimento que supera radicalmente toda a medida humana.

Regressemos à literatura do Holocausto, em cujo contexto, como tínhamos já visto, se colocam questões muito semelhantes. Se considerarmos uma obra entre todas canónica como Se questo è un uomo, de Primo Levi, poderá parecer à primeira vista que o autor não consegue escapar à fixação na sua experiência de Auschwitz. No seu breve prefácio, Levi sublinha ser desnecessário indicar que não existe no livro nada que seja inventado. A obra foi escrita pouco tempo após a libertação e foi publicada logo em Outubro de 1947, embora apenas tivesse obtido ressonância depois de a poderosa editora Einaudi ter, em 1958, feito sair uma nova edição. É indiscutível que o autor, enquanto pessoa, ao trazer à memória o que sofreu, revive todos os horrores do campo de extermínio; toda a narrativa está repassada de luto e indignação. Mas o escritor que está a compor um livro de memórias constrói, ao mesmo tempo, uma distância em relação ao vivido que lhe permite assumir, não apenas o papel da vítima, mas também da testemunha e do acusador. As pequenas vitórias no quotidiano do campo que vão sendo narradas e que permitem a sobrevivência, através da obediência absoluta aos códigos do campo e da adoção dos comportamentos adequados, são narradas de uma forma que faz com que o carácter de estado de exceção da aparente normalidade se mantenha sempre presente. Esta dissonância contém um potencial cómico que Levi não sublinha ao longo do relato, mas que se exprime ao fio deste na forma de uma atitude irónica que, apesar de muitíssimo discreta, é bem palpável. Pretende-se que o leitor reconheça como o quotidiano do campo é terrível, mas, ao mesmo tempo, também absurdo e mesmo, por vezes, ridículo. Assim, por exemplo, na primeira parte do capítulo "O último", fala-se de uma "menaschka", isto é, um recipiente para sopa toscamente improvisado, que tem o aspecto de um "objecto neolítico". O narrador salienta em que medida a simples posse deste 
recipiente elevou o seu estatuto social no campo: ele representa literalmente "um diploma de nobreza, é um símbolo heráldico" (Levi 129). Justamente o gesto discreto de auto-ironia aqui e noutros passos do relato permite ao narrador construir para si próprio uma espécie de posição de soberania, que está em contradição com a situação humilhante e desumana que está a ser narrada.

Gestos semelhantes de ironia e auto-ironia encontram-se noutros relatos autobiográficos, por exemplo, em Sem destino, de Imre Kertész. Limitar-me-ei, todavia, a um exemplo particularmente marcante, o romance Eine Reise (Uma viagem), de H. G. Adler. Uma viagem - concluído em 1951, mas publicado apenas em 1962 pela Bibliotheca Christiana, uma editora pequena pouco representativa - é um romance autobiográfico: conta a deportação de Praga do próprio Adler, juntamente com a mulher e outros membros da família, nenhum dos quais sobreviveu. O fundamento autobiográfico surge, no entanto, no romance, submetido a uma forte lógica de estranhamento. A estação principal da viagem é o campo de Theresienstadt, que recebe no romance o nome fictício irónico de Ruhenthal. ${ }^{3}$ Outros locais recebem igualmente nomes fictícios, cujo uso, por si só, mostra que o romance não está orientado no sentido do testemunho directo: trata-se de um texto muito complexo, narrado através de técnicas refinadas de escrita modernista, que poderão fazer recordar o chamado "realismo mágico" pela acentuação da natureza fantasmagórica de coisas e situações. Peter Suhrkamp terá dito uma vez que, enquanto fosse vivo, este romance jamais seria publicado na Alemanha. ${ }^{4}$ Desconheço os motivos desta tirada, mas é fácil especular que a irritação do poderoso editor não pode deixar

\footnotetext{
3 Literalmente, "vale do repouso".

${ }^{4} \mathrm{O}$ episódio é referido por Jeremy Adler no seu posfácio à nova edição do romance (1999: 310).
} 
de estar relacionada como a forma desconcertantemente distanciada como a deportação e o extermínio são narrados no romance.

Noutros estudos, debrucei-me com mais demora sobre o romance de Adler (Ribeiro, 2008; 2013). No presente contexto, limitar-me-ei a sublinhar o modo como este romance polifónico trabalha do princípio ao fim com os meios do grotesco como estratégia principal de estranhamento. Veja-se o exemplo seguinte:

O crematório é prático e higiénico. É uma das mais belas e úteis invenções modernas, que não apenas o espírito, mas também o sentimento refinado de um coração esclarecido concebeu, para se fazer depressa o que tem de ser feito e poupar muito trabalho aos coveiros. Os fornos podem funcionar a óleo, mas, no estado actual da ciência, é aconselhável o aquecimento com energia eléctrica. (210-11)

O carácter chocante desta descrição é calculado ao pormenor pela voz narrativa. Uma viagem representa, na verdade, o exemplo singular de um romance sobre o Holocausto em que as palavras alemão, judeu ou campo não ocorrem uma única vez. A composição polifónica da narrativa e a constante refração dos acontecimentos através da visão e do comentário gera a imagem de um mundo fantasmagórico que, no seu conjunto - de modo reforçado pela inversão distópica do topos da viagem - se constitui como signo de um desenraizamento radical e, assim, no domínio da ficção, constrói perante os olhos do leitor uma imagem do Holocausto, que nunca é nomeado enquanto tal, como uma sequência de imagens de pesadelo. Esta estratégia de ficcionalização assume recorrentemente traços grotescos e surreais, muito próximos da dimensão do cómico. Poderia dizer-se, em resumo, que a resposta de Adler à pergunta sobre a possibilidade da representação da violência absoluta é, sem dúvida, inteiramente afirmativa, mas que essa representação só se 
afigura viável se a testemunha como sujeito sofredor, como vítima, se retirar para segundo plano e for capaz de encontrar ou inventar modos de objetivação da sua experiência assentes numa lógica de distância e estranhamento que não hesita em utilizar os recursos do cómico e do grotesco para se constituir enquanto tal. Assim, este romance enfileira na linha daqueles textos que, segundo Terrence Des Pres, "se recusam a tomar o Holocausto nos seus próprios termos avassaladores, embora a base de que dependem seja uma memória muito nítida de acontecimentos reais" (220).

Em obras da chamada segunda geração, como, por exemplo, os romances dos autores austríacos Robert Schindel ou Doron Rabinovici, encontram-se sem dificuldade processos de estranhamento análogos. Em geral, como terá ficado claro, a questão difícil que me propus abordar só pode ter respostas simultaneamente nos planos ético e estético, que, neste contexto, se revelam verdadeiramente inseparáveis. A questão da legitimidade ética conflui, neste contexto, com a capacidade de gerar respostas credíveis no plano estético, isto é, dito de outro modo, o processo de constituição de autoridade que permite à vítima, como referi a abrir, pôr em causa um estatuto de menoridade hetero-atribuído e afirmar a sua autonomia como sujeito depende por inteiro da capacidade de construção de um universo retórico em que a memória viva do sofrimento se articule com dimensões de distância e estranhamento. O que implica que a pergunta, entre todas difícil, sobre se a dimensão do cómico poderá ser adequada à abordagem de situações de violência extrema não consinta respostas em geral, antes tenha sempre de ser aferida a partir da especificidade de cada caso particular. 


\section{Obras citadas}

Adler, H. G. Eine Reise. Wien: Zsolnáy, 1999. Print.

Améry, Jean. Jenseits von Schuld und Sühne: Bewältigungsversuche eines Überwältigten. München: dtv, 1988. Print.

Des Pres, Terrence. "Holocaust Laughter?" [1988]. Org. Berel Lang. Writing and the Holocaust. New York: Holmes and Meier, 1991, 216-33. Print.

Fassin, Didier and Richard Rechtman, org. L'Empire du traumatisme: Enquête sur la condition de victime. Paris: Flammarion, 2007. Print.

Kertész, Imre. "Der Holocaust als Kultur". Org. J. Améry. Eine Gedankenlänge Stille, während das Erschießungskommando neu lädt: Essays. Reinbek: Rowohlt, 2002. Print.

Kraus, Karl. Os últimos dias da humanidade. Trad. António Sousa Ribeiro. Lisboa: Antígona, 2004. Print.

Levi, Primo. Se questo è un uomo: La tregua. Milano: Einaudi, 1993. Print.

Katholisches Institut für Medieninformation, org. Lexikon des internationalen Films. Reinbek bei Hamburg: Rowohlt, 1995. Print.

Nietzsche, Friedrich. Jenseits von Gut und Böse, Kritische Studienausgabe, vol. 5. Org. Giorgio Colli and Mazzino Montinari. München: dtv, 1999, 9-243. Print.

Ribeiro, António Sousa. "Cartografias do não-espaço: viagens ao fim do mundo na literatura do Holocausto". Revista Crítica de Ciências Sociais 83 (2008): 5-18. Print.

- "Umbrüche der Erinnerung: H. G. Adlers exzentrische Stellung im Kanon der Holocaust-Literatur". Org. Dagmar von Hoff et al. Poetiken des Auf-und Umbruchs. Frankfurt am Main, Peter Lang, 2013, 53-61. Print.

Tabori, George. Mein Kampf. G. Tabori. Meine Kämpfe. Frankfurt am Main: Fischer, 1991, 5-99. Print.

—. Mutters Courage. Berlin: Wagenbach, 2010. Print.

Weil, Simone. 'L'Illiade ou le poème de la force'. S. Weil. Oeuvres. Paris: Gallimard, 1999. Print.

Weiss, Peter. Die Ermittlung. P. Weiss. Stücke I. Frankfurt am Main: Suhrkamp, 1976, 257-449. Print.

Wieviorka, Annette. L'ère du témoin. Paris: Hachette, 2002. Print. 